\title{
Quantifying Latin American firms' exposure to external factors
}

Analysis of Latin America' s Corporations as a Rational Response to The Economic Environment Present in The Region

\author{
Part III
}

\section{Sergio A. Pernice, Mariano Fernandez and María A. Alegre}

\author{
Universidad del CEMA \\ Av. Córdoba 374 \\ (C1054AAP) Capital Federal \\ Argentina
}

\footnotetext{
${ }^{1}$ The views and opinions expressed in this publication are those of the authors and are not necessarily those of the Universidad del CEMA.
} 


\begin{abstract}
This is the last of a series of three working papers analyzing the basic characteristics of the economic environment in which Latin American firms operate and the optimal design of incentive programs compatible with such environment. Executive pay-for-performance compensation schemes are usually based on stock returns. However, stock returns change in response to forces beyond management control (e.g., market crushes). The economic environment in which Latin American firms operate is highly unstable, which means that this is a very important limitation for Latin American firms.
\end{abstract}

In the present paper, we present a procedure to decompose variability in stock returns in order to identify and measure components that respond to external factors beyond management control. For this, we have created indices that capture statistically the external influences that affect stock returns. We show how such indices can be used to construct a risk profile that allows management to know to what extent observed outcomes depend on external factors, versus their own actions. In addition, these indices can be used as a basis to develop "indexed options": financial instruments designed to factor out the effects of external risks, making it possible for executives to be evaluated only on the basis of the value they generate. We show that these indices can be developed out of purely local information, but that the solutions tend to be moderately unstable, which implies that compensation instruments developed with this methodology should be of relatively short maturity. 


\section{Introduction}

When firms are public, stock value provides a key metric to evaluate top management performance. Owners would like to have managers make decisions that increase stock value, making them wealthier ${ }^{2}$. Managers monitor stock price as a way to obtain feedback regarding the value creation implications of their decision-making. In order to align incentives between managers and owners, executive compensation packages are structured with pay for performance schemes that in the case of public firms tend to depend on stock price.

However, firm outcomes are a function of multiple factors, and the quality of top management decision-making is only one of those factors. The value of stock can go up or down in response to management actions, but can also vary as a function of forces beyond management control such as changes in the economic cycle and many other external shocks.

For example, in the United States, firms answered calls in the 1980s to tie compensation more closely to shareholder wealth with increased grants of executive stock options. With the long bull market in the 1990s, stock options unfairly rewarded executives for the market's success instead of their own contribution. On the other side of this problem, the market crush of NASDAC in the 2000s produced stock price declines that left many executive stock options out-of-the-money, penalizing managers for negative outcomes caused by forces beyond their control ${ }^{3}$.

Any firm using stock value as a benchmark for pay for performance schemes among its executives will face this difficulty. However, the problem is especially salient in Latin America. In previous work ${ }^{4}$ we have shown that Latin American firms face a highly

\footnotetext{
2 Jensen, M. "Foundations of Organizational Strategy", Harvard University Press, 1998. Brickley, J.; Smith, C.; and Zimmerman, J. "Managerial Economics and Organizational Architecture", Second Edition, McGrawHill Irwin, 2001

3 Johnson, S.A. \& Tian, Y.S. (2000). Indexed executive stock options. Journal of Financial Economics, 57, 35-64.

${ }^{4}$ Pernice, S.A. \& Fernandez, M. (2004). Macroeconomic Environment and Nature of Capital Markets in Latin-American Countries. UCEMA Working Papers. Unpublished manuscript.
} 
unstable economic environment. This instability determines that more than $50 \%$ of the daily stock return variability of a typical company depends on factors beyond management control, compared to about $10-20 \%$ in the US. This, in turn, implies that it is very difficult and costly to provide the right incentives to the firm executives. Since the stock return depends on so many external factors in Latin America, contracts that make executive compensation dependent on stock returns will loose their incentive effects.

As we mentioned before, managers monitor stock price as a way to obtain feedback regarding the value creation implications of their decision-making. Given that Latin American firms face a highly unstable economic environment, it becomes very difficult for managers to determine if their actions either create or destroy firm value. This is compounded by what is known in the behavioral finance literature as the self-attribution bias: people attribute successful outcomes to their own skill but blame unsuccessful outcomes on bad luck ${ }^{5}$. This hobbles managers in two ways. First, managers cannot learn from mistakes because they will not see them as mistakes. Second, managers will assume they have been skilled or smart when they have just been lucky.

The purpose of the present paper is to present a procedure to decompose variability in stock returns in order to identify and measure components that respond to external factors beyond management control. For pay for performance schemes, this allows the generation of "indexed options": financial instruments designed to factor out the effects of external risks, making it possible for executives to be evaluated only on the basis of the value they generate. These compensation contracts are beginning to be used in some American companies, and one of the authors (SP), in collaboration with Mercer Human Resources Consulting, recently developed the first indexed option executive compensation plan for a Latin American firm ${ }^{6}$. In order to develop indexed options, we need to create an index that captures as much as possible the external influences that affect stock returns. Then, the value of the compensation contract is made to depend on the difference between the value

\footnotetext{
5 Shefrin, H. (1999). Beyond Greed and Fear: Understanding Behavioral Finance and the Psychology of Investing. Financial Management Association Survey and Synthesis Series.

${ }^{6}$ See www.cema.edu.ar/bladex for plan details.
} 
of the stock and the value of a moving strike price that depends on this index. We dedicate this paper to set the basis for the construction of these indices for Latin American firms. As we will show in the present work, such indices can also be used to analyze and measure the sources of external risk exposure faced by managers. In other words, they allow us to construct a risk profile that indicates to what extent observed outcomes depend on external factors, versus management actions. This constitutes objective feedback that should limit the scope of attribution problems.

As demonstrated in our previous work ${ }^{4}$, the macroeconomic environment prevalent in emerging countries during the nineties has been extremely unstable. Recurring crises in emerging economies seem to affect other apparently unrelated emerging countries, which makes the macroeconomic environment very noisy. But how exactly does this noise affect a specific given stock? This question is of fundamental importance if we want to filter out such noise when analyzing the performance of a given stock.

Before we continue, let us clearly state what do we mean by "filtering out the noise" on a given stock. Suppose that the returns of the stock of a company $i$ can be decomposed into external (to the firm) factors, and that $r_{a}, r_{b}, r_{c}$, and $r_{d}$ are the returns of indices that we take as proxies for these factors, then we have the following regression equation:

$$
r_{i}=\beta_{1}+\beta_{2} r_{a}+\beta_{3} r_{\mathrm{b}}+\beta_{4} r_{\mathrm{c}}+\beta_{5} r_{\mathrm{d}}+\varepsilon_{i}
$$

We interpret the portion of the returns of the stock $i$ due to these factors as outside management control. If we want to isolate only the portion of the stock return under management control, this is simply the part $\varepsilon_{\mathrm{i}}$. Therefore, "filtering out the noise" means: 1) finding the right factors and their corresponding proxies; 2) calculating the corresponding $\beta \mathrm{s}$; and 3) performing the following subtraction:

$$
r_{i}-\beta_{1}-\beta_{2} r_{a}-\beta_{3} r_{\mathrm{b}}-\beta_{4} r_{\mathrm{c}}-\beta_{5} r_{\mathrm{d}}=\varepsilon_{i}
$$

The percentage of volatility explained by these factors gives us a measure of how much of the stock return is due to external factors. This corresponds to the $\mathrm{R}^{2}$ of the regression. 
The problem of isolating the portion of a Latin American stock return that management can actually control appears then to be very difficult conceptually. The stock of a company in an emerging country depends on the macroeconomic environment, and this environment in turn depends on external factors such as crises in other emerging countries. Thus, in order to clean up the stock performance from all these external influences it would seem necessary to use an extremely complex combination of indices. Each one of these indices would act as a proxy for a possible source of noise. However, the nature of financial markets, in particular their "efficiency", induces us to search for ways to simplify this approach.

The so-called "semi strong" form of market efficienc y claims that all publicly available information is rapidly reflected in the prices of securities. But before working out the consequences of market efficiency for our problem at hand, we need to analyze if it really holds for our region. In our previous work we have shown that, as measured by whatever standard parameter you may choose (e.g., market capitalization to GDP ratio, volatility, liquidity, concentration, etc.), Latin American equity capital markets are underdeveloped. How can we then simultaneously claim that they are nevertheless efficient? The reason is that efficiency is a very robust notion. Financial market efficiency requires only a few informed market makers and investors in order to work. As reviewed in our previous work, the available studies on this subject, most of them unpublished, show that when transaction costs are taken into account, the behavior of Latin American financial markets is consistent with the concept of efficiency.

What consequences can we draw from the efficiency of equity markets for our problem at hand? In another words, what can we conclude from the fact that all publicly available information is rapidly reflected in the prices of securities? Qualitatively we can anticipate that when an event such as a crisis in emerging country A occurs, and influences equity prices in another unrelated country B, it is likely that such effect will be rapidly reflected in country B' s equity index. Thus, if we want to filter out the effect of a crisis in country A on the stocks of country B, due to the efficiency of markets we will only need to take into 
account the effect of the crisis in country B's equity index. In other words, market efficiency allows us to simplify the problem of filtering out noise from a global problem involving global indices as proxies for global factors to a far simpler local problem where only local indices are considered. In the present chapter we explore this possibility.

Quantitatively the above arguments translate into the fact that if the markets are efficient, then the explanatory power (the $\mathrm{R}^{2}$ of the regression) of local indices for the returns of stocks should not be significantly different from the explanatory power of a set of global indices. We show in this chapter that this is indeed the case. In the process, we develop a methodology that allows Latin American companies to have a clear picture of their risk profile. That is, we are able to point out the sources of risk that affect a given company and how these sources change over time. In addition, we show that in many cases, not only do the local indices have the same explanatory power than a set of global indices, but their coefficients are actually more stable through different time periods.

This paper is organized as follows. First, we develop a methodology to decompose the risk profile of Latin American companies into global, regional, country, and industry risks, and we present some examples that show the power of this methodology to detect the main sources of risk during periods of crisis. Second, we test the capacity of local indices to capture the information contained in the global indices. In a sense, this can be considered a test of market efficiency. Consistently with efficiency, we show that local indices, including country and industry indices, do capture basically all the relevant information. This result is of great importance because it allows us to reduce the filtering problem from a global to a local one. Third, we study the stability of the local solution of the filtering problem. We find that, in general, the solutions are not very stable. This is consistent with our conjecture that in emerging countries, and in particular in Latin American countries, the optimal incentive contract is shorter than in developed countries. Fourth, we illustrate these three points with a set of tables that take a close look at a number of companies of interest. We conclude with a discussion of how the construction of these indices should be adapted in order to develop indexed stock options tailor made for a specific firm. 


\section{Risk Profile}

We start with a global model. In order to capture factors influencing the returns of a given stock with a small number of free parameters, we first study a model of the following form:

$r_{i, j}=\beta_{1}+\beta_{2} r_{\mathrm{S} \& \mathrm{P} 500}+\beta_{3} r_{\text {Lat.Ind } j}+\beta_{4} r_{\text {country } j}+\beta_{5} r_{\text {Ind } i j}+\varepsilon_{i, j}$

In this regression model, $r_{i, j}$ refers to the daily returns of company $i$ of country $j . \quad r_{\mathrm{S} \& 5500}$ refers to daily returns of the S\&P500 index, taken as a proxy for global influences over the

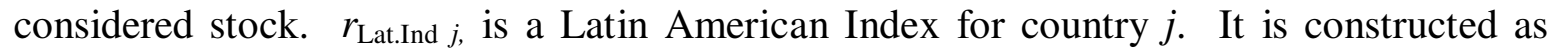
follows: if $\mathrm{j}$ is, say, Brazil, then $r_{\text {Lat.Ind } j}$ is the arithmetic average of the daily returns of the indices of the other Latin American countries considered (i.e., Argentina, Chile, Colombia, Mexico and Venezuela). Note that the index of Brazil is not considered in this index. We also explored how the results change when a market capitalization weighted index is considered instead of the arithmetic average used here. We found that the results basically do not change, which tells us that our results are robust. The Latin American Index is meant to capture Latin American effects affecting the returns of company $i, j$. The next index, $r_{\text {country } j}$, is the local equity index (e.g., Bovespa for Brazil) meant to capture country specific effects. $r_{\text {Ind } i, j}$ is a local industry index constructed as the arithmetic average of the daily returns of companies of the same country and industry as the company considered that at the same time are sufficiently liquid. Finally, $\varepsilon_{i, j}$ refers to the component of the returns of company $i, j$ that can not be explained by the previous factors. This component is usually called firm specific and can be attributed to executive decision-making. The solution of the filtering problem within this structure is then to find the coefficients $\beta$ that best fit such equation for the historic values considered. We use the standard least square methodology for this.

A model like the one presented above is at the same time sufficiently general and manageable. However, as it stands, is does not allow us to decompose the influences over the stock into unequivocal sources as required in order to construct a risk profile of the 
company. Mathematically, the reason is that the explanatory variables co-vary with each other. But underlying these covariances are deep reasons that one should consider in order to understand the true meaning of a risk profile and act accordingly.

We want to answer the question of what proportion of the stock volatility is due to global, regional, local and industry specific events. But in the above regression model, the explanatory variables co-vary with each other and thus, we cannot isolate the proportion of stock volatility explained by each index. We need to transform the above model into an equivalent model but with de-correlated variables. The problem is that, although this point is technical, there are infinitely many ways to de-correlate variables. Thus, which one should we choose?

To select the right set of variables we were guided by the following observation: in general (but not always), emerging markets tend to be more influenced by global events than the other way around. For example, a fall in the S\&P500 will likely induce a fall in Bovespa but a fall in the Brazilian index will probably not even make a dent on the US index. The following graph represents this asymmetry in the information spill over:

\section{Information Spill Over}

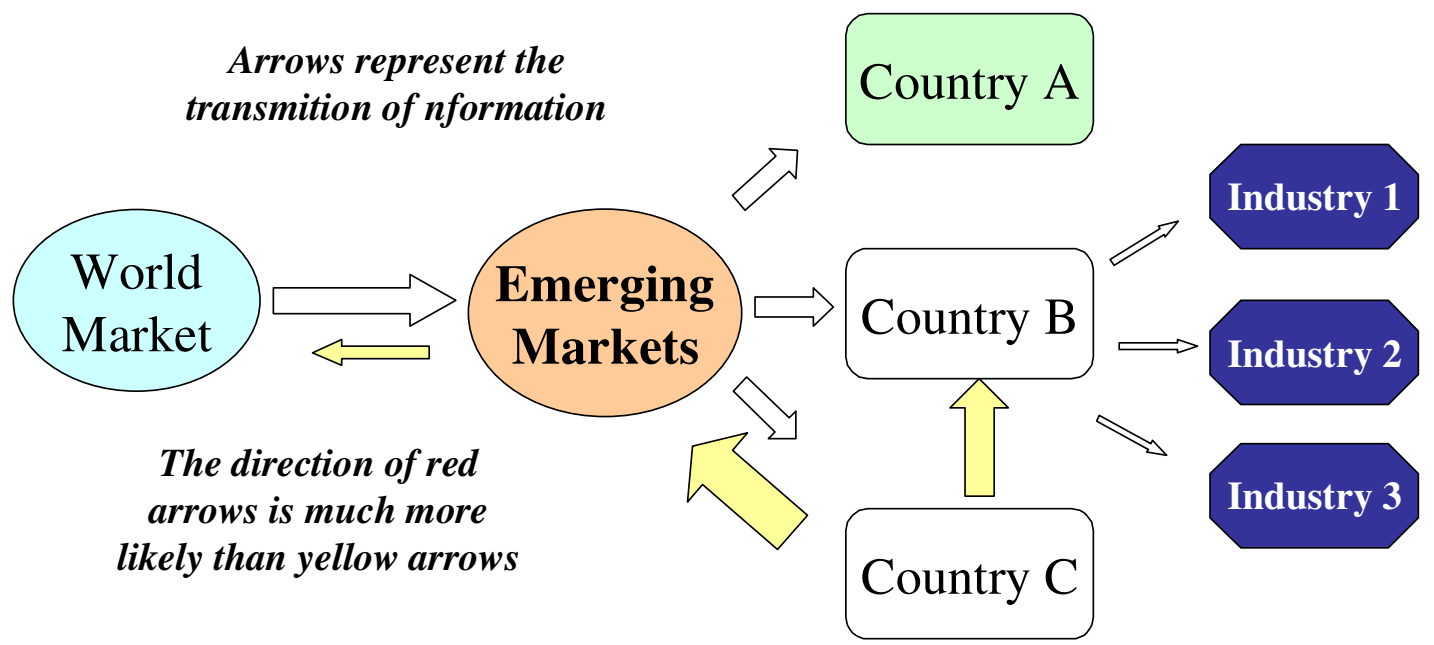


Based on this observation regarding the direction of influences between the variables of interest, we choose our de-correlated variables in the following way ${ }^{7}:$ 1) The global index remains unchanged. 2) We subtract from the regional index the variability already explained by the global index, obtaining in this way a regional index de-correlated to the global index. 3) We subtract from to the country index the variability already explained by the global and regional indices, creating a new country index de-correlated with the previous two indices. 4) We do a similar job with the industry index. We illustrate the procedure in the following graphs, where we go from a situation that could be represented by:

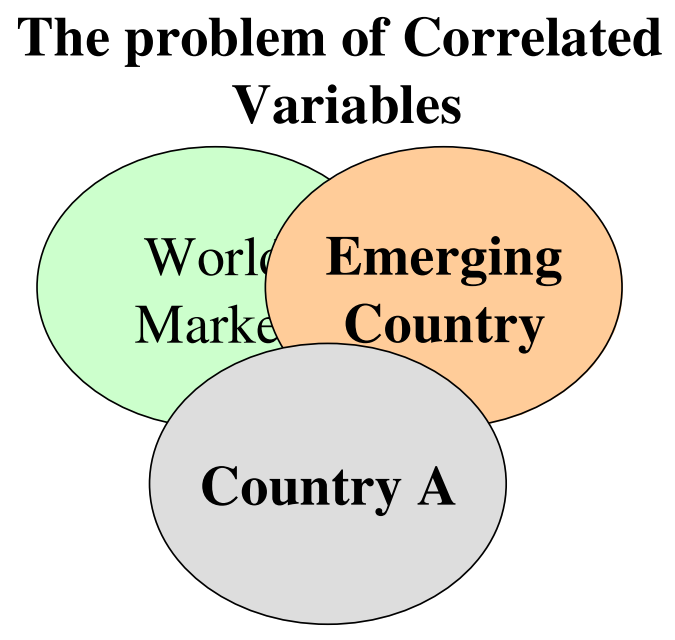

To a situation represented by:

\footnotetext{
${ }^{7}$ Our de-correlation mechanism works like this: the returns of the "global index" are left unchanged. The returns of the Latin American index $r_{\text {Lat.Ind } j}$ get replaced by a variable that we call $r^{*}$ Lat.Ind $j$, explicitly constructed as a linear combination of $r_{\mathrm{S} \& \text { P500 }}$ and $r_{\text {Lat.Ind } j}$ such that it is de-correlated to the S\&P500 (Corr $\left(r_{\mathrm{S} \& \mathrm{P} 500,} r_{\text {Lat.Ind } j}^{*}=0\right)$. The returns of the country index $r_{\text {country } j}$ get replaced by a variable $r_{\text {country } j}$ that is linear combination of $r_{\mathrm{S \& P500}}, r^{*}{ }_{\text {Lat.Ind } j}$ and $r_{\text {country } j}$ simultaneously de-correlated with $r_{\mathrm{S \& P500}}$ and $r_{\text {Lat.Ind } j}$ (Corr $\left(r_{\mathrm{S \& P} 500, j}, r_{\text {country }}^{*}\right)=0$; Corr $\left.\left(r_{\text {Lat.Ind } j}^{*}, r_{\text {country }}^{*}\right)=0\right)$. Finally, the returns of the local industry index $r_{\text {Ind } i, j}$ get replaced by a variable $r_{\text {Ind } i, j}^{*}$ that is a linear combination of $r_{\text {S\&P500, }} r_{\text {Lat.Ind } j}, r_{\text {country } j}$ and $r_{\text {Ind } i, j}$ simultaneously de-correlated with $r_{\text {S\&P500, }} r_{\text {Lat.Ind } j}$ and $r_{\text {country } j}\left(\operatorname{Corr}\left(r_{\text {S\&P500, } j}, r^{*}{ }_{\text {Ind } i, j}\right)=0\right.$; Corr $\left(r_{\text {Lat.Ind } j}, r_{\text {Ind } i, j}^{*}\right)=0$; Corr( $\left.r_{\text {country }}^{*}, r_{\text {Ind } i, j}\right)=0$ ).
} 


\section{De-Correlated Variables}


It is important to understand that in going from the original model of correlated variables to the new model of de-correlated variables, the explanatory power of the model (measured by its $\mathrm{R}^{2}$ ) remains the same. The only difference between results obtained with the new model versus the old one, is that now we are able to decompose the explained portion of the stock return of a company into global, regional, local and industry components. In this way, we can construct an unambiguous risk profile of a company. We should however interpret the results with care because we have in a sense imposed a cause-effect structure in our algorithm (from global, to regional, to local, etc.). Although this generally corresponds to what we see in markets, it does not always work this way (for example, the Asian crisis did for a while affect global indices such as the S\&P500).

The graphs presented below correspond to the risk profile of four companies listed in Table 1.

Table 1

\begin{tabular}{l|c|c|}
\hline \multicolumn{1}{|l}{ Country } & \multicolumn{1}{c|}{ Firm } & Sector \\
\hline Argentina & YPF & Oil and Energy \\
\hline Brazil & ITAU Bank & Banking Sector \\
\hline Chile & $\begin{array}{c}\text { Compañía de Telefonos } \\
\text { CTC }\end{array}$ & Telecomunication \\
\hline México & Bancomer & Banking Sector \\
\hline
\end{tabular}

The periods studied are presented in Table 2. 
Table 2

\begin{tabular}{|lcc|}
\hline \multicolumn{3}{|c|}{ Sample } \\
\hline & Start Date & End Date \\
Full Sample & $02 / 07 / 93$ & $13 / 02 / 02$ \\
Mexican Crisis & $02 / 12 / 94$ & $30 / 06 / 95$ \\
Asian Crisis & $03 / 06 / 97$ & $01 / 12 / 97$ \\
Russian Crisis & $04 / 08 / 98$ & $12 / 02 / 99$ \\
Brazil Crisis & $01 / 12 / 98$ & $30 / 06 / 99$ \\
\hline
\end{tabular}

Note that the sub-periods are explicitly chosen to be the most volatile six-month long subperiods possible. They correspond to one month before and five months after a given crisis. The country indices used are in Table 3.

Table 3

\begin{tabular}{|cc|}
\hline Country & Country Index \\
\hline Argentina & Merval \\
\hline Brazil & Bovespa \\
\hline Colombia & IGBC \\
\hline Chile & IPSA \\
\hline México & INMEX \\
\hline Venezuela & IB Caracas \\
\hline
\end{tabular}

The composition of the local industry index is given for the companies listed in Table 4 .

Table 4

\begin{tabular}{|c|c|l|}
\hline \multicolumn{2}{|c|}{ Country } & \multicolumn{1}{c|}{ Fector } \\
\hline Argentina & Oil and energy & $\begin{array}{l}\text { P Com } \\
\text { Sol Petróleo }\end{array}$ \\
\hline Brazil & Banking Sector & $\begin{array}{l}\text { Bradesco } \\
\text { B Do Brazil } \\
\text { Banespa } \\
\text { Unibanco }\end{array}$ \\
\hline Chile & Telecomunications & $\begin{array}{l}\text { ENTEL } \\
\text { TELEX B } \\
\text { INTECHI }\end{array}$ \\
\hline Mexico & Banking Sector & $\begin{array}{l}\text { Banamex } \\
\text { Banorte } \\
\text { Grupo F Inbursa }\end{array}$ \\
\hline
\end{tabular}


The corresponding analyses for all the other companies studied are presented in a table at the end of this paper.

Each graph compares, for the four companies in Table1, the risk profile of the full sample with the risk profile of the sub-period corresponding to the chosen crisis. Note that in these graphs, the explained portion of volatility is normalized to $100 \%$ since the purpose of these graphs is to show the relative importance and changes in the explanatory variables.

In the first graph, we see that the Mexican crisis affected the Argentinean, Brazilian and Chilean companies through the Latin index. That is, this index increases its explanatory power during the crisis as compared with the full sample. This is consistent with what we would expect intuitively, since the effects of the Mexican crisis remained always bounded to Latin America. Interestingly, for the Mexican company, the effect was felt mostly as an industry effect, again the method gives the right answer since the Mexican company considered is a Bank and the Mexican crisis was essentially a Banking crisis.

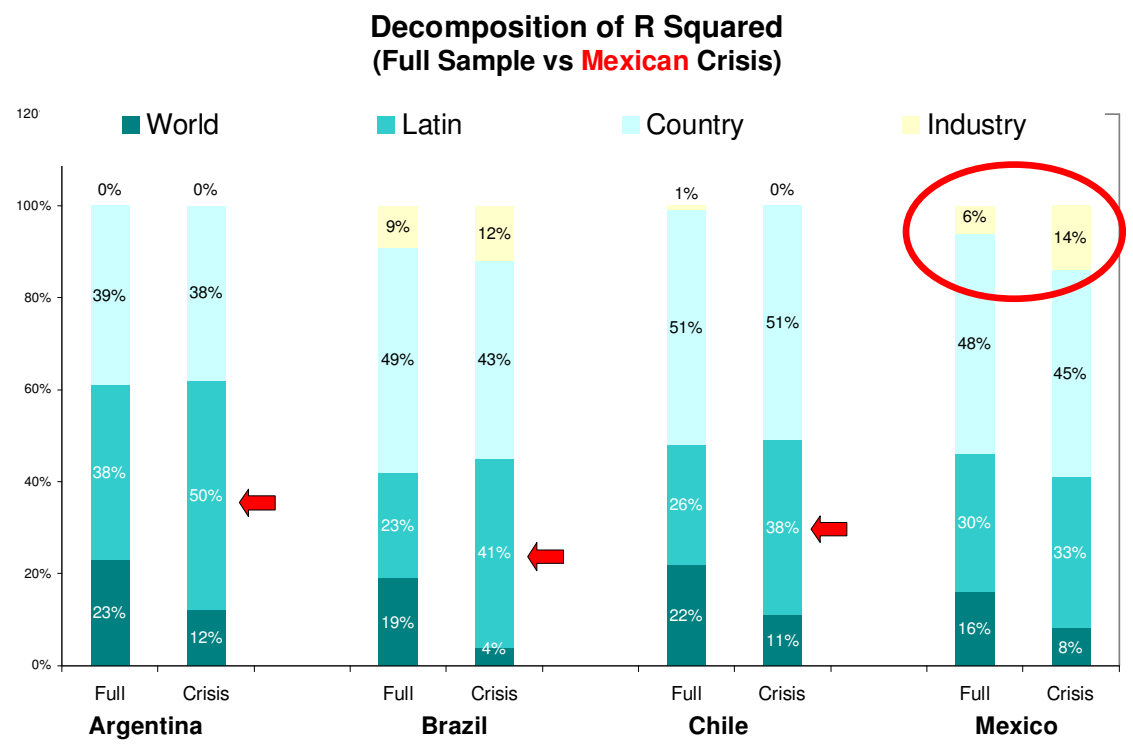

The second graph describes the effects of the Asian crisis. Among all the emerging market crises of the nineties, this was definitely the most global, beginning in July of 1997 with the Bath devaluation and ending on October the 23rd with the run over the Hong Kong 
currency. The contagion to Latin America was then through the global markets. Our methodology captures this by showing that it is the global index the one that increases the most its explanatory power in that period.

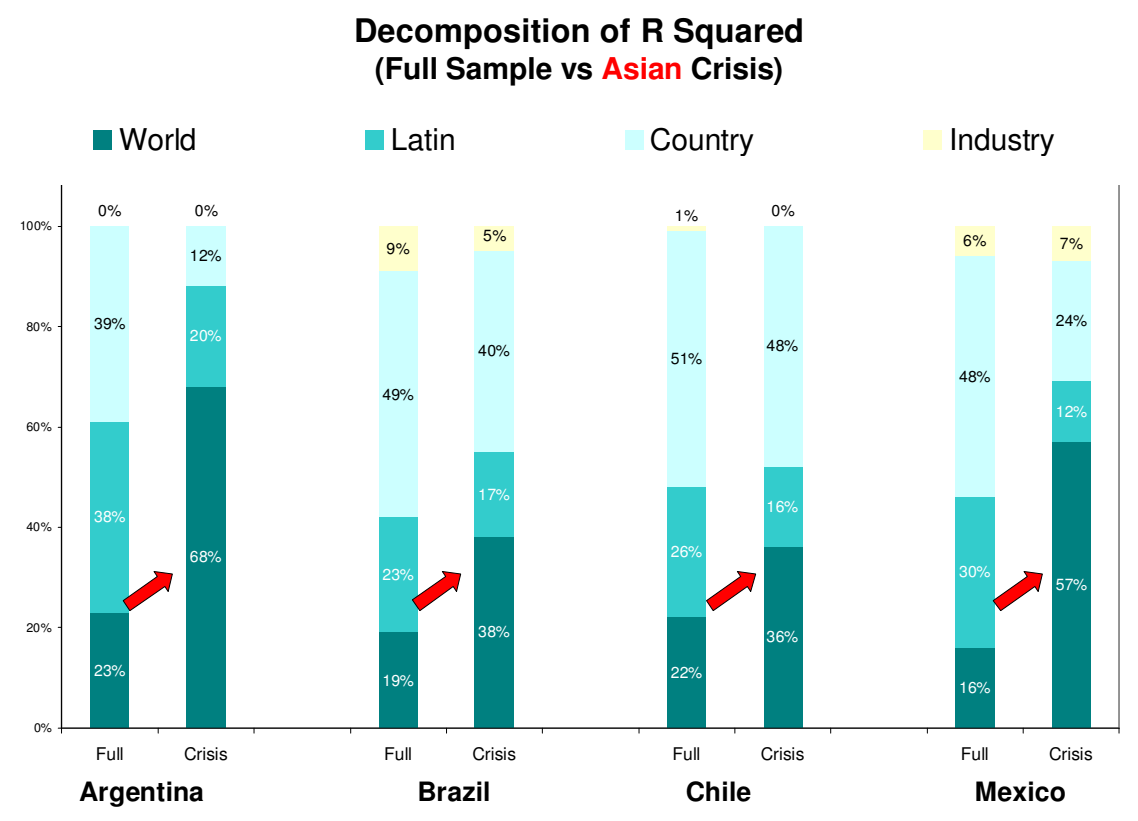

The third graph shows the effects of the Russian crisis. Although it did affect the global markets for a while its main contagion effects where bounded to emerging markets. We see that our methodology captures this by showing that both the world and the regional indices increased their explanatory power. 


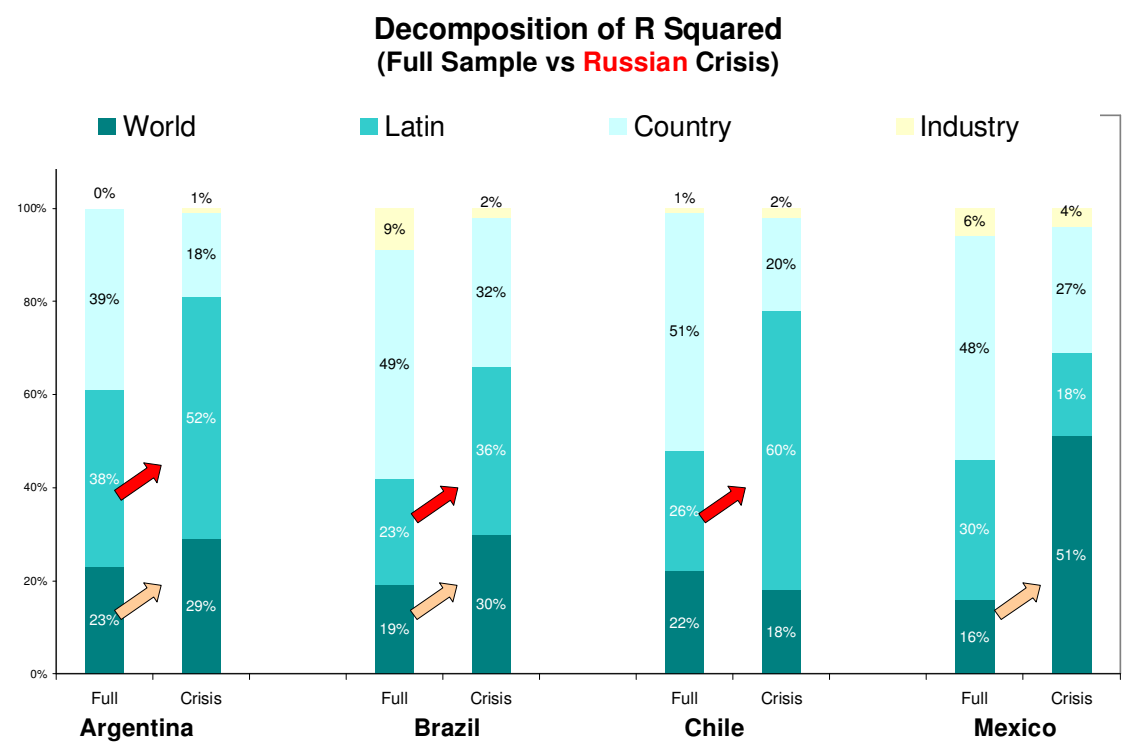

Finally, the fourth graph shows the effects of the Brazilian crisis over the companies selected in Table 1. Note that the Brazilian company gets affected mainly through its industry, again related to the fact that the chosen company is a bank. For the Argentinean and Chilean companies, the effects came mainly through the country index since these two countries were relatively more affected by the Brazilian crisis than the rest of the Latin American countries considered in our regional index. By the time of the Brazilian crisis, Mexico was already tied to the US through NAFTA. That is why the effects for the Mexican company are better captured by the global index. 


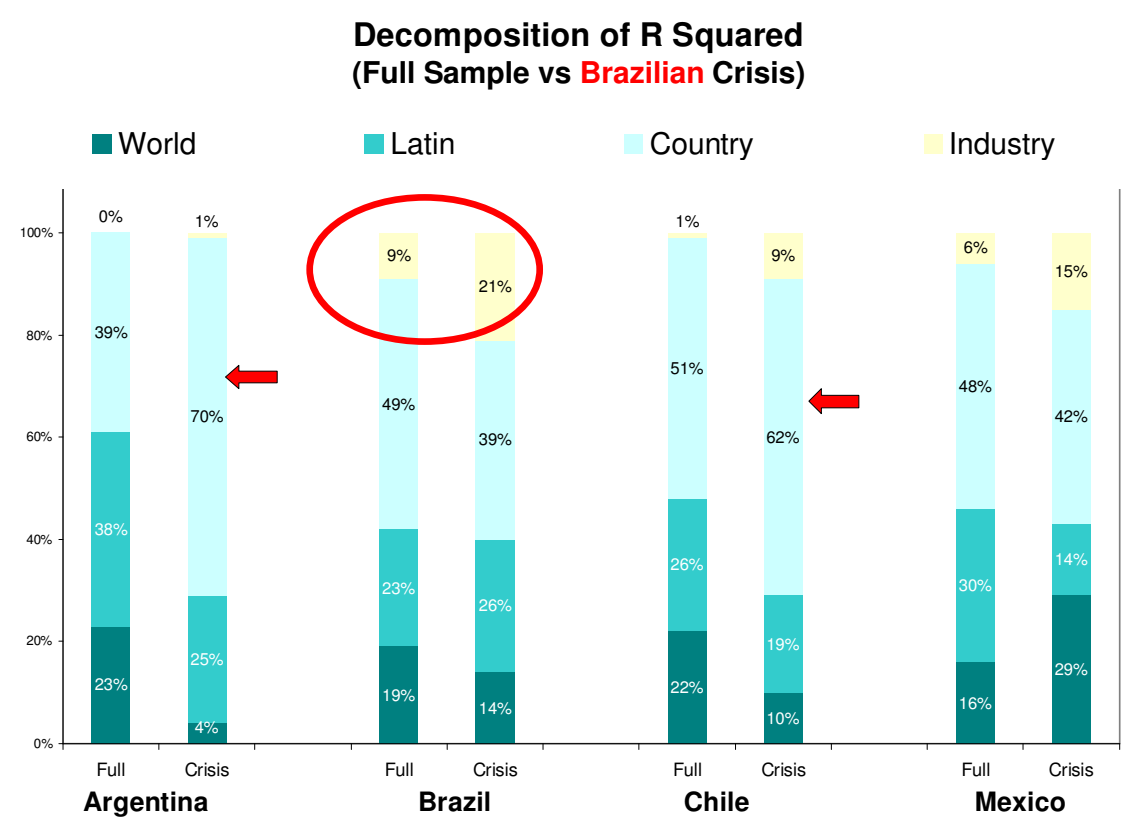

Overall, we note that for the companies studied, on average about $20 \%$ of their explained volatility is due to global effects, about $30 \%$ is due to regional effects, about $47 \%$ is due to country effects, and only about $3 \%$ is due to industry effects. This relatively low impact of the industry specific effects might indicate the market power of the companies considered.

We conclude that our methodology reflects the impact of the crises as one would expect, and therefore the risk profiles it provides are probably an accurate picture of the influences the companies are subject to.

\section{Global vs. Local Models (or about market efficiency)}

Having developed a robust methodology for constructing the risk profile of Latin American companies, we now proceed to study to what extent purely local models are able to capture the information contained in the global model presented in the previous section. As we have already discussed, contrary to intuition, if the markets are efficient the two models should be essentially equivalent. The ultimate purpose of doing this exercise is to bind the 
selection of companies to choose from to construct optimized indices for specific companies. As we will see next, as expected from efficiency, local models capture essentially all the information contained in the global model, so we can already confirm that the construction of optimized indices becomes a manageable problem.

We consider two local models and compare them to the global one of the previous section. The first one consist of simply a country index model:

$$
r_{i, j}=\beta_{1}+\beta_{2} r_{\text {country } j}+\varepsilon_{i, j}
$$

while the second one consists of a country index plus an industry index (constructed as before) model:

$$
r_{i, j}=\beta_{1}+\beta_{2} r_{\text {country } j}+\beta_{3} r_{\text {Ind } i j}+\varepsilon_{i, j}
$$

As a measure for the explanatory power of the models, we consider the corresponding $\mathrm{R}^{2}$. Using daily data, we analyze the full sample mentioned in the previous section, plus the sub-periods corresponding to the crises. For YPF, the Argentinean company, the results are the following: 




The graphs show that the explanatory power remains essentially the same when we compare between the global and local models, consistently with efficiency. The lack of increased explanatory power of the industry index suggests that the company studied has considerable market power and is unaffected by industry events. Note finally that an $\mathrm{R}^{2}$ of $55 \%$ is large by international standards. Furthermore, the $\mathrm{R}^{2}$ is even larger during periods of crises, consistently with intuition that in such periods stock changes are driven mostly by external factors. 


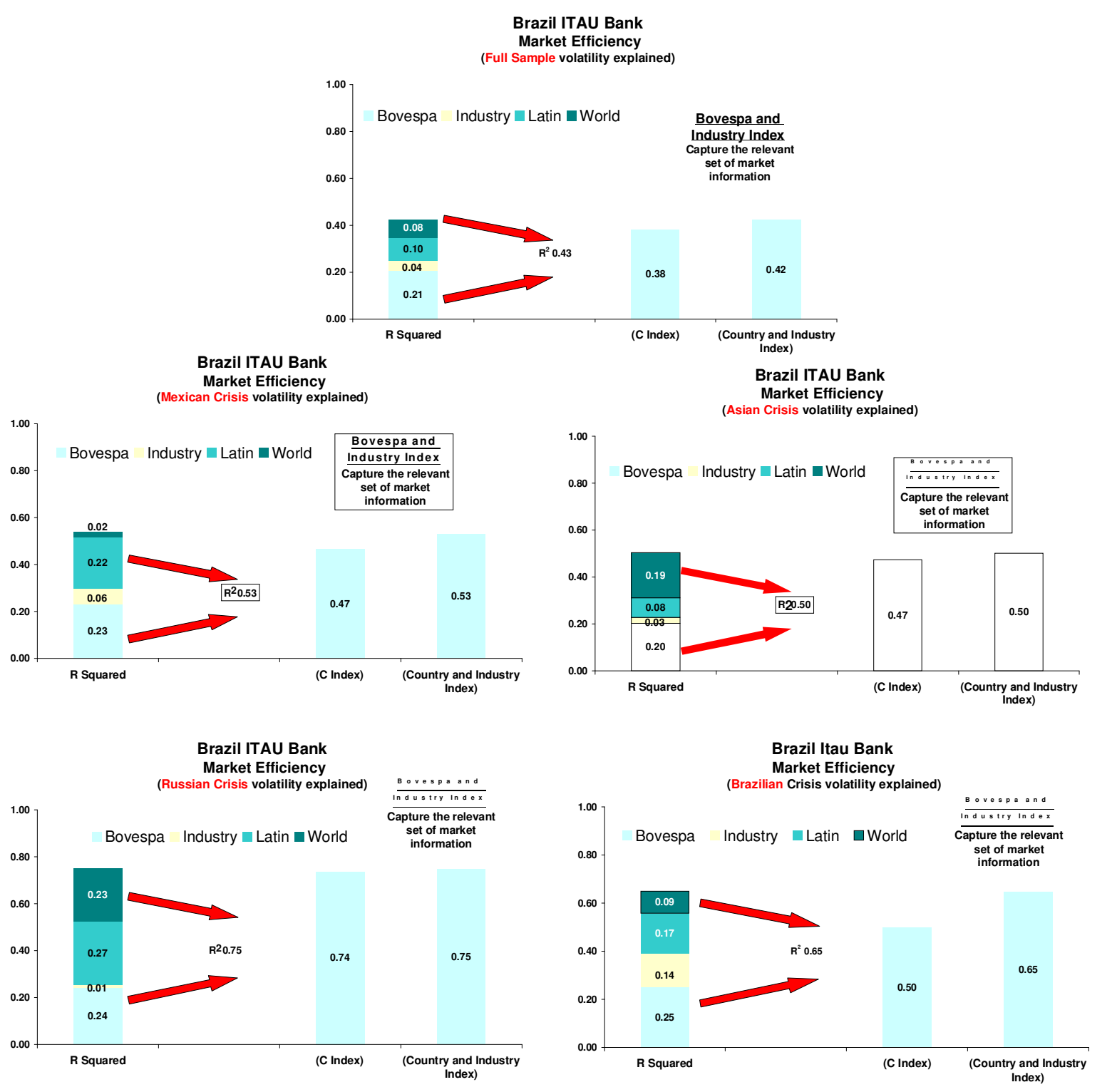

For ITAU, the Brazilian company, we note that the simplest country index model does loose some information but the model including the industry index captures essentially all the information contained in the global model. Once again, local models are sufficient but in this case the data suggest that the banking industry in Brazil is not as monopolized as the oil industry in Argentina. 


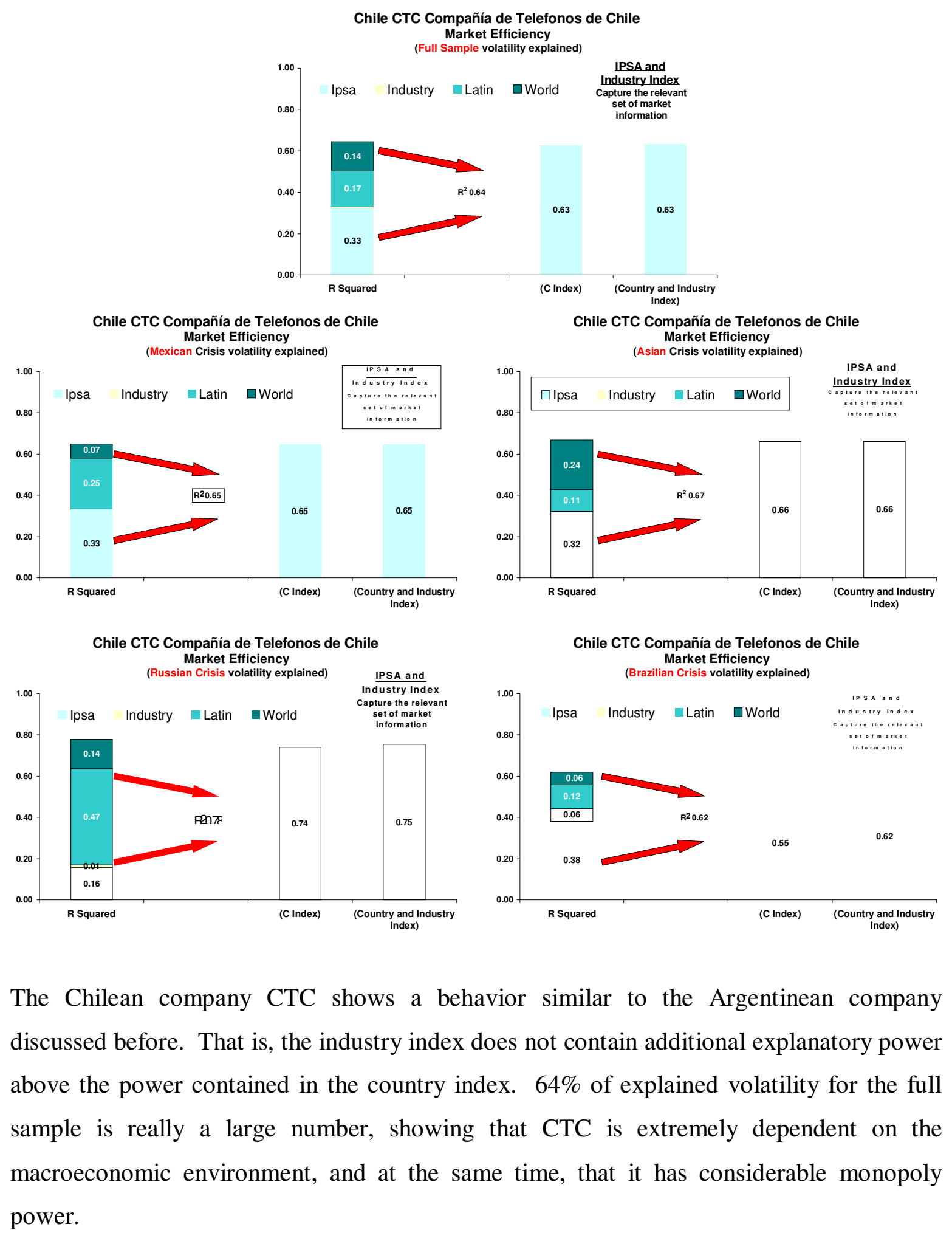




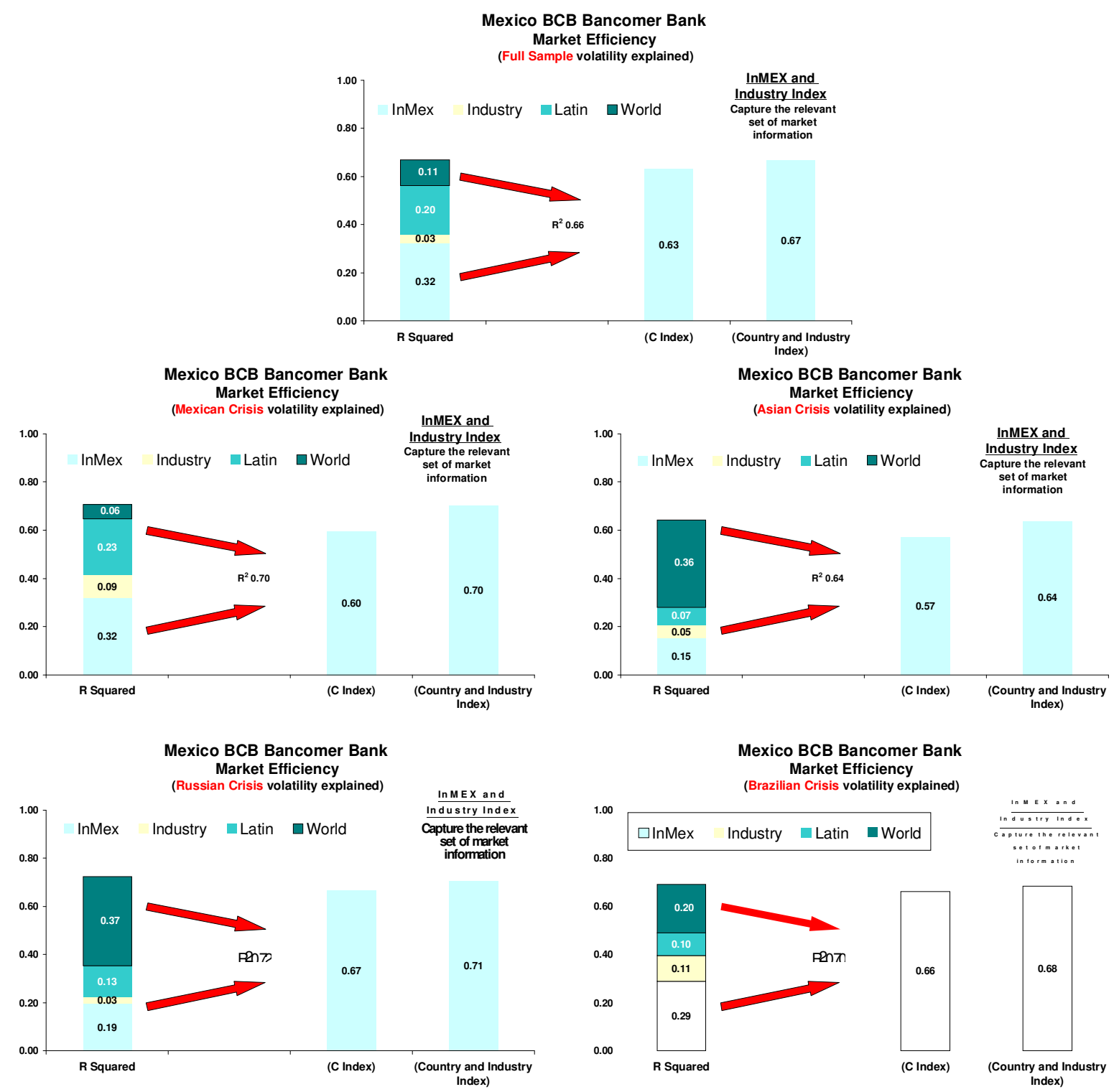

As in the Brazilian case, BCB Bancomer Bank of Mexico is subject to important influences from industry events, which suggest a competitive banking industry. At the same time, $66 \%$ of its volatility depends on factors beyond management control.

We can derive three main points from these graphs. First, as suggested in the introduction, large proportions of the volatility of Latin American firms depend on factors beyond their control. Second, many of these factors are even beyond the particular country and are truly 
global. Third, from a practical point of view, due to the efficiency of capital markets, local indices capture basically all relevant information about the external influences, which simplifies a future search of optimized indices tailor made for specific companies. The table at the end of this chapter confirms that these conclusions are general and do not depend on the particular companies studied in the above graphs.

\section{Stability of the beta coefficients}

In order to design indexed, equity-based incentive contracts, we need to know the stability of the indices used in these contracts. In terms of our models, this means to study the stability of the beta parameters obtained from the regressions.

The result of a regression analysis for the beta parameters is really a probability distribution on the values these parameters may take. When we say, for example, that beta is 0.728 , we are really saying that the best estimate of the probability distribution that the true beta can take is a Normal Distribution with a mean of 0.728. The other parameter that fixes this distribution is its volatility or standard deviation. In the graphs below, we study how these beta parameters change over the periods studied (again, for both the full sample and the crises periods). We perform these analyses for the simplest local model as well as for the

local model including an industry index. The first number represents the best estimate of beta for the full sample, and the bars represent two standard deviations above and below this number. The next four numbers represents the best estimate of beta plus/minus two standard deviations during the periods of time corresponding to the four crises studied. It is important to know that the selection of these sub-periods during crises makes the observed betas probably the most varying possible. To the extent that all the 2 standard deviation bars have points in common we cannot say that the beta actually changed. 
First we show for YPF the results for the Country plus Industry Index Model:

\section{Beta Merval Stability}



Beta YPF Industry Stability

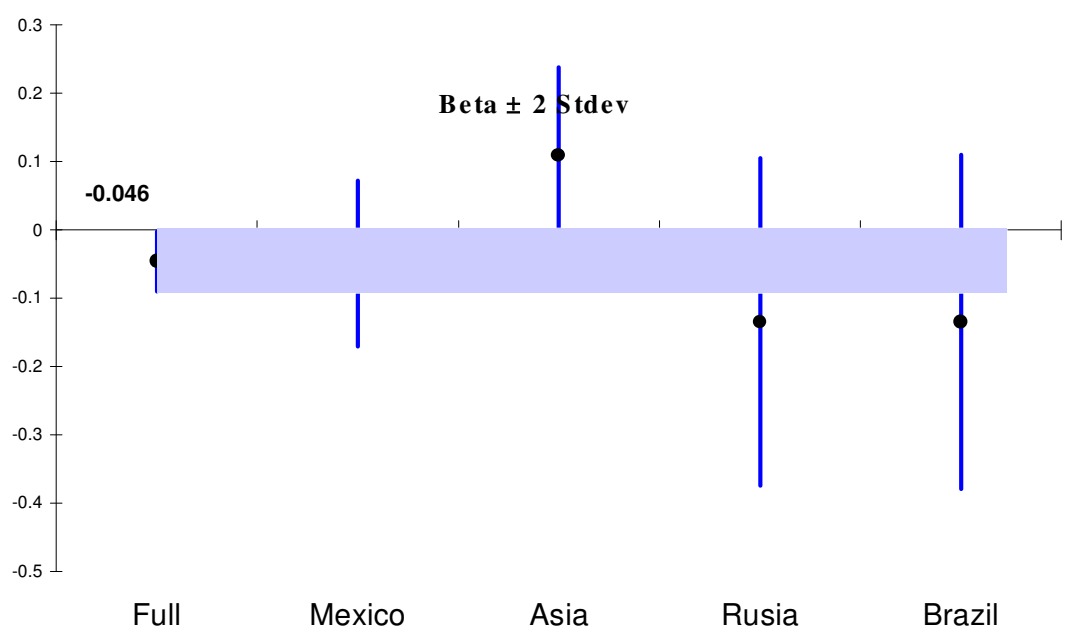

As we see the Beta Merval during de Russian Crisis changed significantly, on the other hand, the Beta Industry for YPF is consistent with zero in every period studied.

The Betas of the Country Index Model for YPF for the different periods behave in a way similar to the beta Merval of the previous model. Note that the two standard deviation bar 
for the full sample is always smaller than the one for the sub-periods (this is simply due to having more data in the full sample).

\section{Beta Merval Alone Stability}



For Itaú the Country plus Industry Index Model gives the following results:

\section{Beta Bovespa Stability}

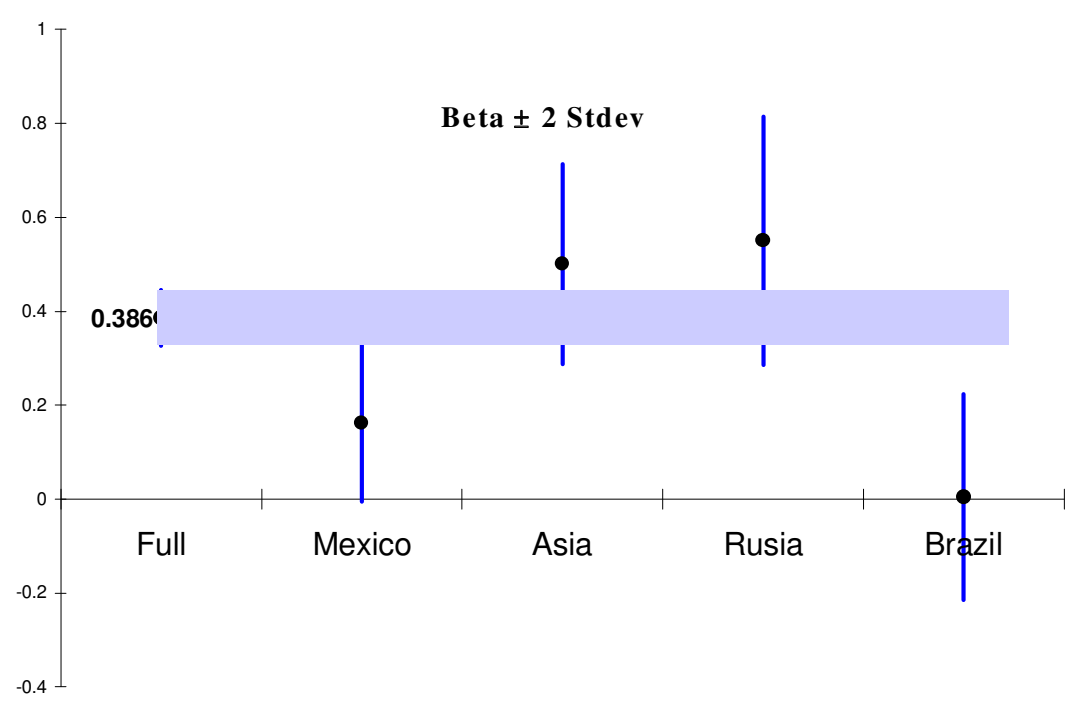




\section{Beta Itau Industry Stability}

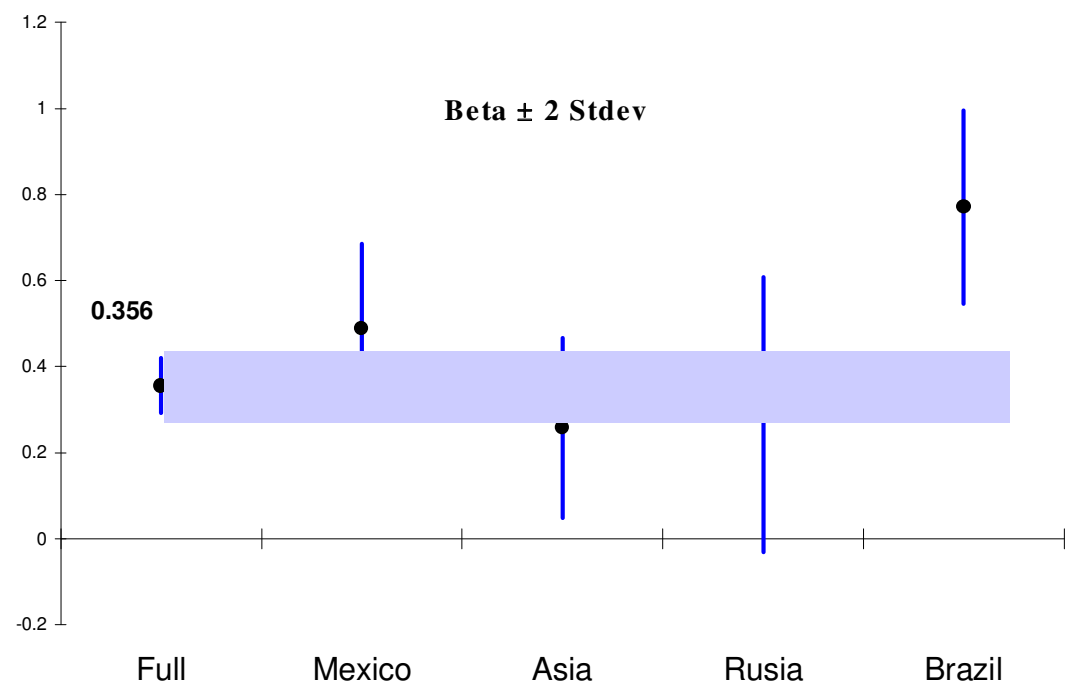

It is evident that during the Brazilian Crisis the changes in both Beta Bovespa and Beta Industry have been dramatic. For the Bovespa alone we see below a more stable behavior of Beta during the Brazilian Crisis.

\section{Beta Bovespa Alone Stability}




For Compañía de Teléfonos de Chile (CTC) the Country plus Industry Model gives the following results:

\section{Beta Ipsa Stability}

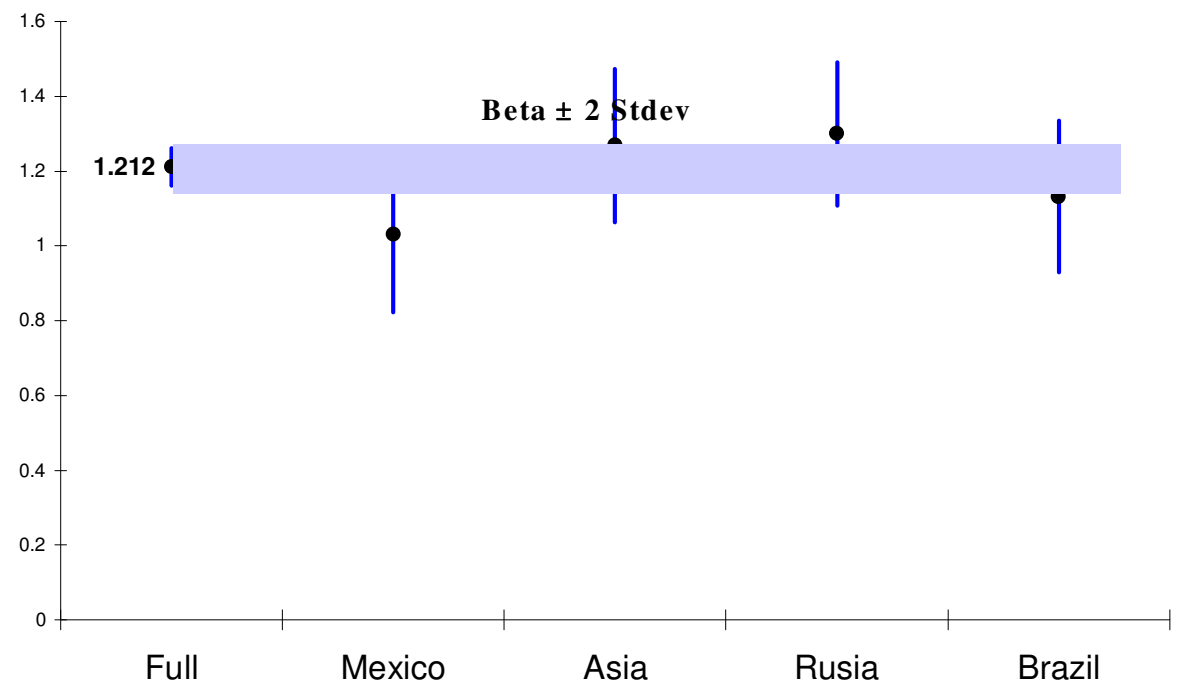

\section{Beta CTC Industry Stability}

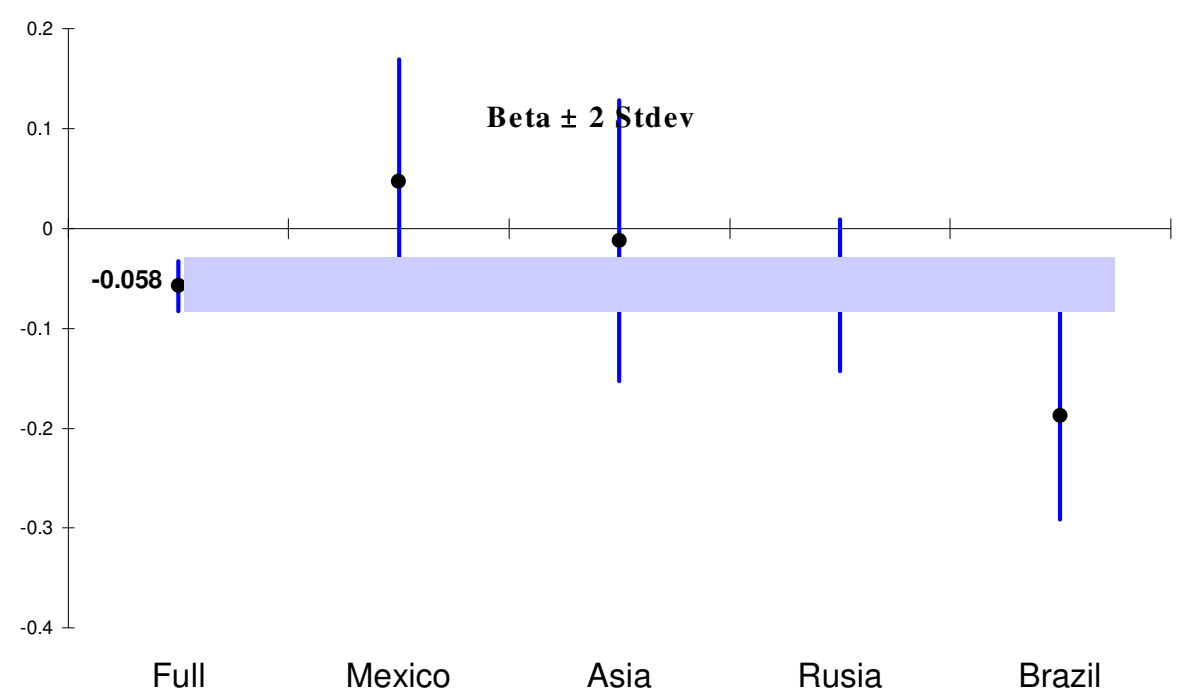

The results for the Country Model are: 


\section{Beta Ipsa Alone Stability}

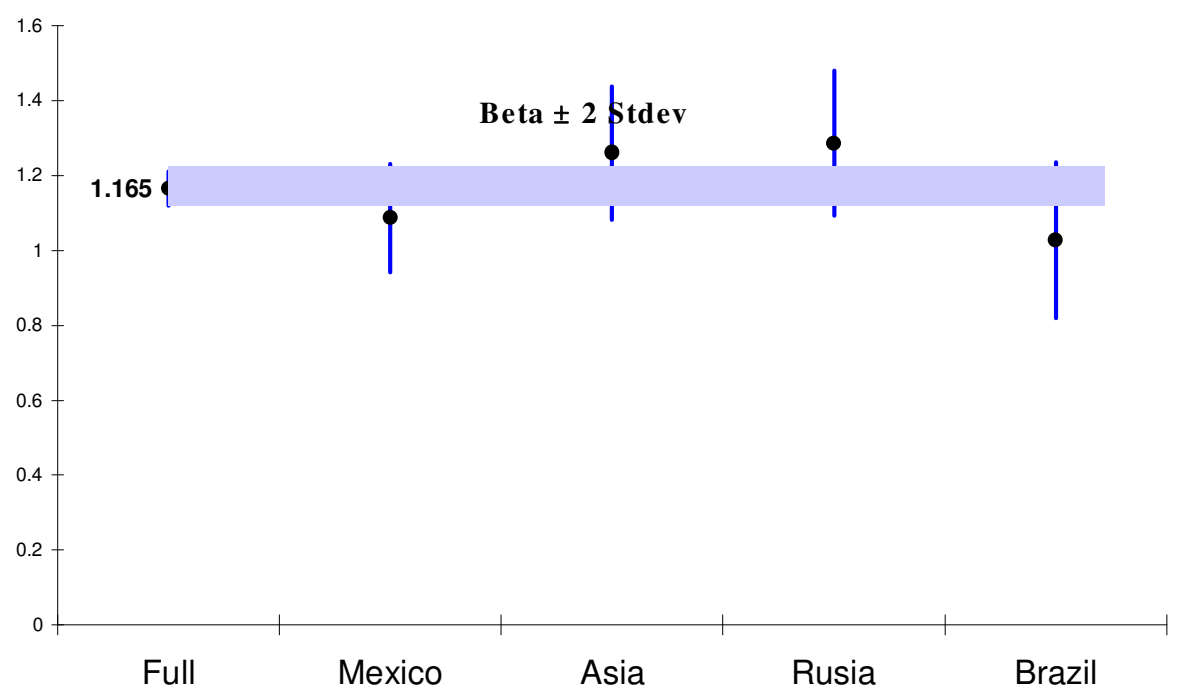

As we see below for Bancomer during the Mexican Crisis, Country and Industry Betas change dramatically but afterwards they stabilize considerably.

\section{Beta InMex Stability}

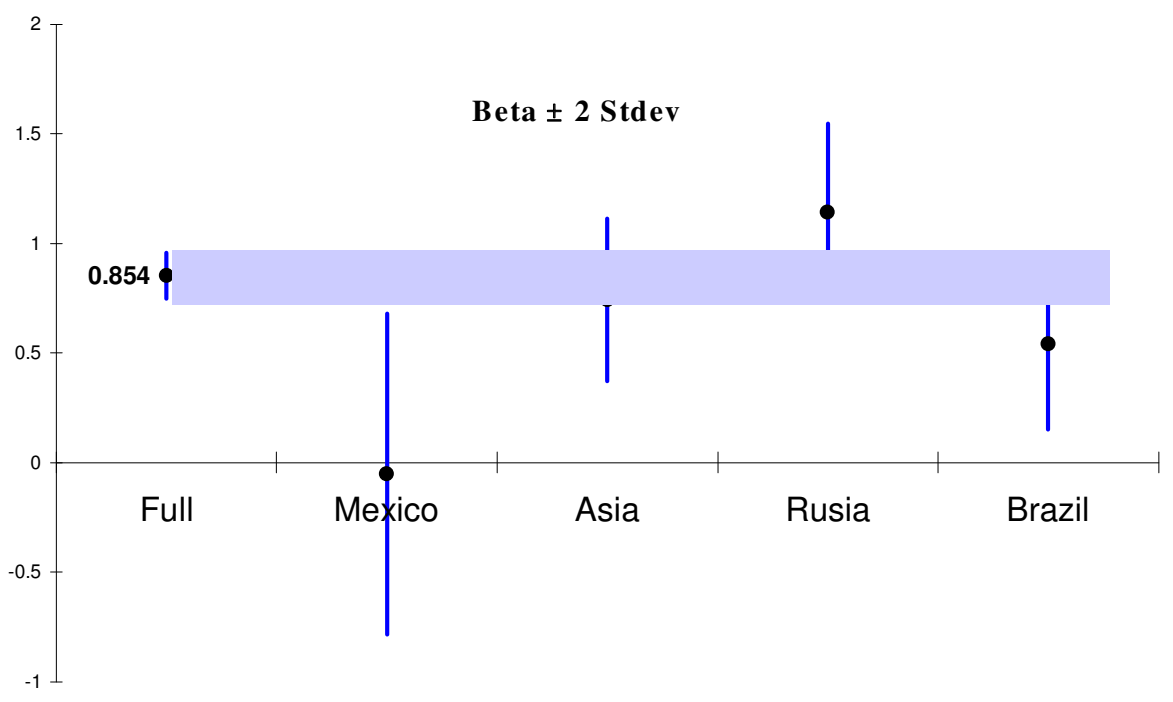




\section{Beta Bancomer Industry Stability}

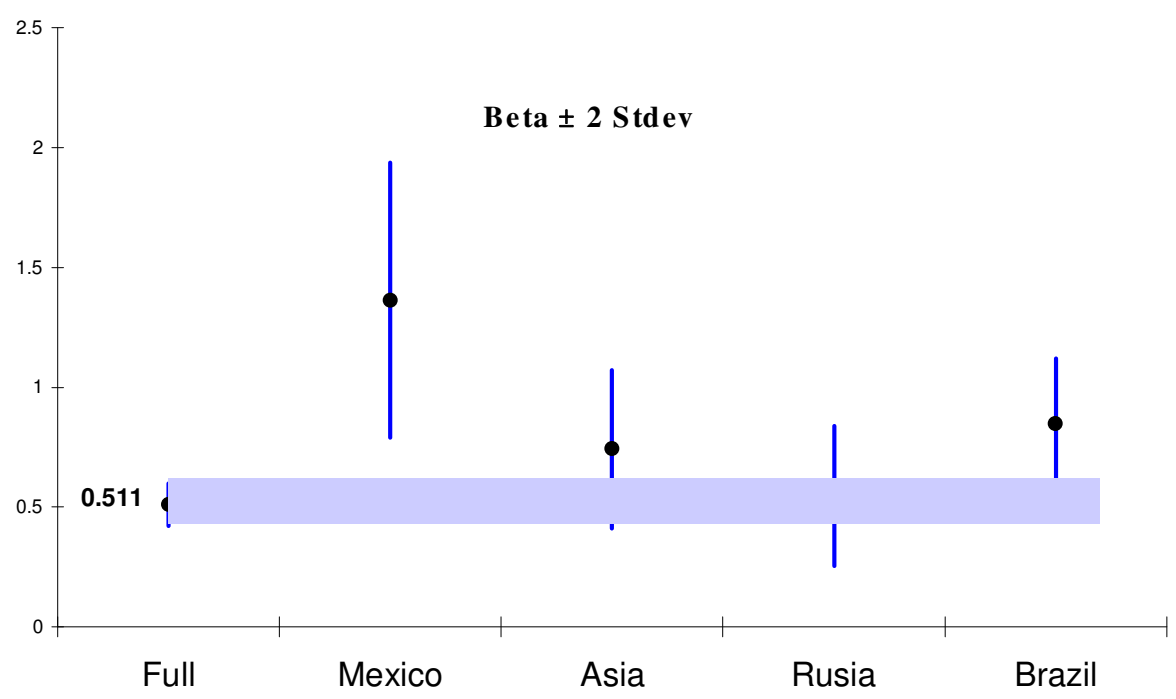

The country model is more stable during the Mexican Crisis.

\section{Beta InMex Alone Stability}

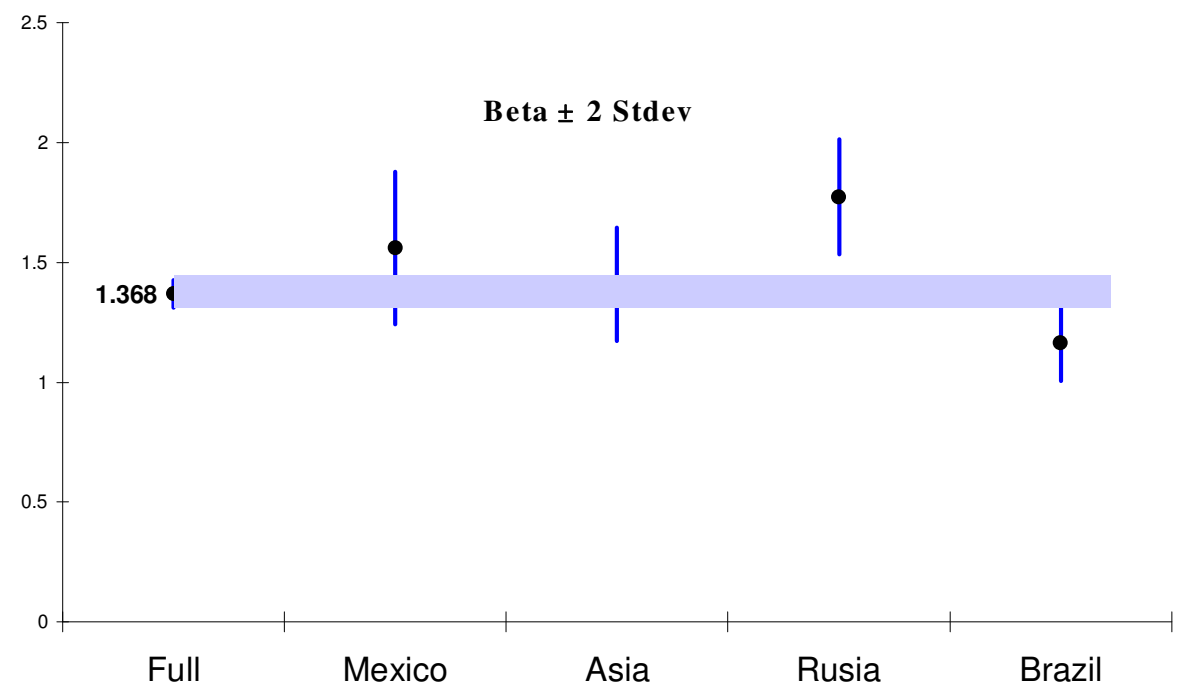

Unfortunately, as the graphs above show, the beta parameters do change with time for both models. This is specially the case in Brazil and Mexico. But even in the other cases, betas vary significantly. The problem with these variation is that if we fix the index for a given 
compensation contract, it may become sub-optimal soon. Therefore, we interpret these results as saying that the optimal contracts will have to have durations much shorter than the one presently used for stock options.

Finally, in the table below, we find the data corresponding to 45 companies of the six Latin American countries of interest in this study.

\begin{tabular}{|c|c|c|c|c|c|c|c|c|}
\hline & \multicolumn{3}{|c|}{ Betas } & \multirow{2}{*}{ R Squared } \\
\hline & COUNTRY & SECTOR & FIRM & PERIOD & Const. & Country & Index Ind. & \\
\hline 1 & Argentina & Oil & YPF & Full Sample & 0,001 & 0,720 & $-0,046$ & 0,540 \\
\hline 2 & Argentina & Oil & YPF & Mexican Crisis & 0,000 & 0,623 & $-0,049$ & 0,692 \\
\hline 3 & Argentina & Oil & YPF & Asian Crisis & 0,000 & 0,606 & 0,109 & 0,699 \\
\hline 4 & Argentina & Oil & YPF & Russian Crisis & 0,000 & 0,993 & $-0,134$ & 0,666 \\
\hline 5 & Argentina & Oil & YPF & Brazilian Crisis & 0,000 & 0,886 & $-0,135$ & 0,496 \\
\hline 6 & Argentina & Oil & Sol Pet & FULL SAMPLE & 0,000 & 0,987 & $-0,265$ & 0,228 \\
\hline 7 & Argentina & Oil & Pcom & FULL SAMPLE & 0,000 & 0,830 & 0,017 & 0,738 \\
\hline 8 & Argentina & Foods & Ledesma & FULL SAMPLE & 0,000 & $-0,042$ & 0,583 & 0,294 \\
\hline 9 & Argentina & Foods & Molinos & FULL SAMPLE & 0,000 & 0,042 & 0,504 & 0,294 \\
\hline 10 & Argentina & Banks & Bansud & FULL SAMPLE & $-0,002$ & 0,568 & 0,497 & 0,468 \\
\hline 11 & Argentina & Banks & Frances & FULL SAMPLE & 0,001 & 0,756 & 0,439 & 0,781 \\
\hline 12 & Argentina & Banks & Galicia & FULL SAMPLE & 0,000 & 0,528 & 0,501 & 0,678 \\
\hline 13 & Argentina & Banks & Río & FULL SAMPLE & 0,000 & 0,577 & 0,317 & 0,581 \\
\hline 14 & Argentina & Banks & Suquía & FULL SAMPLE & 0,000 & 0,353 & 0,424 & 0,500 \\
\hline 15 & Argentina & Siderurgy & Acindar & FULL SAMPLE & 0,000 & 0,923 & 0,238 & 0,650 \\
\hline 16 & Argentina & Siderurgy & Siderca & $\begin{array}{l}\text { FULL SAMPLE } \\
\end{array}$ & 0,000 & 0,845 & 0,177 & 0,667 \\
\hline 17 & Argentina & elecomunicatio & Telefonica & FULL SAMPLE & 0,000 & 0,315 & 0,422 & 0,488 \\
\hline 18 & Argentina & elecomunicatio & Telecom & FULL SAMPLE & 0,000 & 0,720 & 0,305 & 0,676 \\
\hline 19 & Argentina & Beverages & Quilmes & FULL SAMPLE & 0,000 & 0,261 & & 0,086 \\
\hline 20 & Brazil & Banks & ITAU & Full Sample & 0,000 & 0,386 & 0,356 & 0,423 \\
\hline 21 & Brazil & Banks & ITAU & Mexican Crisis & 0,000 & 0,162 & 0,428 & 0,538 \\
\hline 22 & Brazil & Banks & ITAU & Asian Crisis & 0,000 & 0,500 & 0,257 & 0,501 \\
\hline 23 & Brazil & Banks & ITAU & Russian Crisis & 0,000 & 0,550 & 0,288 & 0,748 \\
\hline 24 & Brazil & Banks & ITAU & Brazilian Crisis & 0,000 & 0,005 & 0,771 & 0,647 \\
\hline 25 & Brazil & Banks & Banespa & FULL SAMPLE & 0,000 & 0,514 & 0,377 & 0,269 \\
\hline 26 & Brazil & Banks & Bradesco & FULL SAMPLE & 0,000 & 0,576 & 0,298 & 0,521 \\
\hline 27 & Brazil & Banks & Do Brazil & FULL SAMPLE & 0,000 & 0,647 & 0,225 & 0,376 \\
\hline 28 & Brazil & Banks & Unibanco & FULL SAMPLE & 0,000 & 0,347 & 0,248 & 0,218 \\
\hline 29 & Brazil & Foods & Sadia & FULL SAMPLE & 0,000 & 0,542 & & 0,303 \\
\hline 30 & Brazil & Oil & Petrobras & FULL SAMPLE & 0,000 & 0,062 & & 0,020 \\
\hline 31 & Brazil & Beverages & Ambev & FULL SAMPLE & 0,000 & 0,763 & 0,027 & 0,497 \\
\hline 32 & Brazil & Beverages & Antarctica & FULL SAMPLE & 0,000 & 0,049 & 0,659 & 0,296 \\
\hline 33 & Brazil & Beverages & Polar & FULL SAMPLE & 0,000 & $-0,169$ & 0,811 & 0,201 \\
\hline 34 & Brazil & Mines & V Rio Doce & FULL SAMPLE & 0,000 & 0,518 & 0,102 & 0,275 \\
\hline 35 & Brazil & Mines & Caemi & FULL SAMPLE & 0,000 & 0,401 & 0,161 & 0,170 \\
\hline 36 & Brazil & Mines & Magnesita & FULL SAMPLE & 0,000 & 0,409 & 0,118 & 0,168 \\
\hline 37 & Chile & elecomunicatio & стC & Full Sample & 0,000 & 1,212 & $-0,058$ & 0,633 \\
\hline 38 & Chile & elecomunicatio & стC & Mexican Crisis & 0,000 & 1,030 & 0,047 & 0,647 \\
\hline 39 & Chile & elecomunicatio & стC & Asian Crisis & 0,000 & 1,268 & $-0,012$ & 0,661 \\
\hline 40 & Chile & elecomunicatio & CTC & Russian Crisis & 0,000 & 1,299 & $-0,067$ & 0,753 \\
\hline 41 & Chile & elecomunicatio & CTC & Brazilian Crisis & 0,000 & 1,132 & $-0,187$ & 0,616 \\
\hline 42 & Chile & elecomunicatio & ENTEL & Full Sample & 0,000 & 0,895 & $-0,001$ & 0,310 \\
\hline 43 & Chile & elecomunicatio & Telex B & Full Sample & 0,000 & 0,689 & 0,028 & 0,045 \\
\hline 44 & Mexico & Banks & Bancomer & Full Sample & 0,000 & 0,854 & 0,511 & 0,666 \\
\hline 45 & Mexico & Banks & Bancomer & Mexican Crisis & 0,000 & $-0,053$ & 1,363 & 0,701 \\
\hline 46 & Mexico & Banks & Bancomer & Asian Crisis & 0,000 & 0,742 & 0,741 & 0,638 \\
\hline 47 & Mexico & Banks & Bancomer & Russian Crisis & 0,000 & 1,140 & 0,548 & 0,705 \\
\hline 48 & Mexico & Banks & Bancomer & Brazilian Crisis & 0,000 & 0,541 & 0,846 & 0,683 \\
\hline 49 & México & Banks & Banorte & Full Sample & 0,000 & 0,600 & 0,392 & 0,510 \\
\hline 50 & Mexico & Banks & INBursa & Full Sample & 0,000 & 0,568 & 0,126 & 0,466 \\
\hline 51 & Mexico & Banks & Banamex & Full Sample & 0,000 & 0,713 & 0,523 & 0,645 \\
\hline 52 & Colombia & Banks & B Bogota & Full Sample & 0,000 & 0,730 & 0,100 & 0,282 \\
\hline
\end{tabular}

\begin{tabular}{|c|c|c|}
\hline \multicolumn{3}{|c|}{ Standard Deviation } \\
\hline Const. & Country & Index Ind. \\
\hline 0,00056 & 0,02465 & 0,02202 \\
\hline 0,00152 & 0,07747 & 0,06054 \\
\hline 0,00121 & 0,07683 & 0,06463 \\
\hline 0,00264 & 0,12414 & 0,11990 \\
\hline 0,00264 & 0,13279 & 0,12221 \\
\hline 0,00130 & 0,08037 & 0,09181 \\
\hline 0,00045 & 0,01856 & 0,01742 \\
\hline 0,00060 & 0,02292 & 0,01738 \\
\hline 0,00064 & 0,02466 & 0,02013 \\
\hline 0,00143 & 0,09704 & 0,08944 \\
\hline 0,00079 & 0,04821 & 0,04450 \\
\hline 0,00090 & 0,05810 & 0,05235 \\
\hline 0,00097 & 0,06200 & 0,05413 \\
\hline 0,00103 & 0,06882 & 0,05927 \\
\hline 0,00047 & 0,02957 & 0,02267 \\
\hline 0,00041 & 0,02487 & 0,01687 \\
\hline 0,00044 & 0,02687 & 0,02273 \\
\hline 0,00037 & 0,01818 & 0,01643 \\
\hline 0,00076 & 0,02539 & \\
\hline 0,00066 & 0,02995 & 0,03202 \\
\hline 0,00221 & 0,08340 & 0,09886 \\
\hline 0,00283 & 0,10655 & 0,10470 \\
\hline 0,00312 & 0,13201 & 0,15995 \\
\hline 0,00242 & 0,10959 & 0,11208 \\
\hline 0,00110 & 0,05157 & 0,05889 \\
\hline 0,00064 & 0,02810 & 0,03071 \\
\hline 0,00087 & 0,03853 & 0,04268 \\
\hline 0,00087 & 0,04089 & 0,04293 \\
\hline 0,00055 & 0,01572 & \\
\hline 0,00101 & 0,02767 & \\
\hline 0,00291 & 0,04707 & 0,03933 \\
\hline 0,00396 & 0,07327 & 0,07254 \\
\hline 0,00498 & 0,09895 & 0,10561 \\
\hline 0,00089 & 0,03189 & 0,02966 \\
\hline 0,00106 & 0,04154 & 0,03707 \\
\hline 0,00102 & 0,03868 & 0,03553 \\
\hline 0,00040 & 0,02505 & 0,01264 \\
\hline 0,00168 & 0,10362 & 0,06139 \\
\hline 0,00114 & 0,10255 & 0,07039 \\
\hline 0,00366 & 0,09547 & 0,03813 \\
\hline 0,00250 & 0,10123 & 0,05202 \\
\hline 0,00060 & 0,03923 & 0,02030 \\
\hline 0,00147 & 0,14580 & 0,11508 \\
\hline 0,00083 & 0,05237 & 0,04424 \\
\hline 0,01068 & 0,36603 & 0,28670 \\
\hline 0,00284 & 0,18444 & 0,16567 \\
\hline 0,00413 & 0,20344 & 0,14628 \\
\hline 0,00028 & 0,19450 & 0,13720 \\
\hline 0,00088 & 0,05849 & 0,04549 \\
\hline 0,00065 & 0,04227 & 0,02973 \\
\hline 0,00081 & 0,05203 & 0,04279 \\
\hline 0,00121 & 0,06772 & 0,05882 \\
\hline
\end{tabular}




\begin{tabular}{|c|c|c|c|c|c|c|c|c|}
\hline & & & & & \multicolumn{3}{|c|}{ Betas } & \multirow{2}{*}{ R Squared } \\
\hline & COUNTRY & SECTOR & FIRM & PERIOD & Const. & Country & Index Ind. & \\
\hline 53 & Colombia & Banks & B Colombia & Full Sample & 0,000 & 0,908 & 0,150 & 0,383 \\
\hline 54 & Colombia & Banks & B Ganadero & Full Sample & 0,000 & 0,762 & $-0,186$ & 0,226 \\
\hline 55 & Colombia & R Materials & Argos & Full Sample & 0,000 & 1,325 & 0,078 & 0,658 \\
\hline 56 & Colombia & R Materials & Caribe & Full Sample & 0,000 & 0,963 & 0,119 & 0,430 \\
\hline 57 & Colombia & Beverages & Bavaria & Full Sample & 0,000 & 1,287 & & 0,474 \\
\hline 58 & Venezuela & Banks & B Provincial & Full Sample & 0,000 & 0,337 & 0,121 & 0,277 \\
\hline 59 & Venezuela & Banks & Eorp Bancari & Full Sample & 0,000 & 0,295 & $-0,150$ & 0,022 \\
\hline 60 & Venezuela & Banks & Mercantil & Full Sample & 0,000 & 0,808 & 0,217 & 0,246 \\
\hline 61 & Venezuela & Banks & UniBanca & Full Sample & 0,000 & 0,561 & 0,097 & 0,112 \\
\hline
\end{tabular}

\begin{tabular}{|r|r|r|}
\hline \multicolumn{3}{|c|}{ Standard Deviation } \\
\hline Const. & \multicolumn{1}{|c|}{ Country } & Index Ind. \\
\hline 0,00120 & 0,06392 & 0,05971 \\
\hline 0,00107 & 0,05765 & 0,04229 \\
\hline 0,00101 & 0,05059 & 0,02917 \\
\hline 0,00130 & 0,08401 & 0,04834 \\
\hline 0,00041 & 0,03178 & \\
\hline 0,00239 & 0,06704 & 0,06882 \\
\hline 0,00156 & 0,14496 & 0,14483 \\
\hline 0,00566 & 0,15708 & 0,19556 \\
\hline 0,00607 & 0,18001 & 0,21030 \\
\hline
\end{tabular}

The table should be read in the following way: consider for example the Brazilian company Ambev, all the numbers are self explanatory except the Industry Index numbers. The industry index is an arithmetic average of the other two Brazilian companies of the beverages sector (Antarctica and Polar). But we also studied these two companies on their own, so for Antarctica for example the Industry Index is the arithmetic average of the other two Brazilian companies of the beverages sector (Ambev and Polar). The companies used to construct the Industry Index were selected as those among the industry that at the same time have reasonably liquid stocks. The low $\mathrm{R}^{2}$ of the Venezuelan companies is due to an extreme lack of liquidity of these companies, which makes the number obtained almost meaningless.

\section{Conclusion}

The purpose of the present paper has been to present a procedure to decompose variability in stock returns in order to identify and measure components that respond to external factors beyond management control. We started by setting up a procedure to capture, using standard regression models, the proportion of the stock volatility of a firm that is due to external factors. We then showed how the explained portion of the stock return of a company can be decomposed into global, regional, local and industry components. In this way, we constructed unambiguous risk profiles that not only tell us exactly to what extent external risk factors are responsible for observed variations in stock returns, but also measure the relative weights that global, regional, local and industry factors have in this regard. A word of caution is required in order to interpret these results as we have imposed a cause-effect structure in our algorithm (from global, to regional, to local, etc.). 
A risk profile with these characteristics can be very informative for managers. It captures the impact that forces beyond their control have on stock returns. In addition, the risk profile tells managers which of these external forces are more relevant for the dynamics of their business and how they change over time.

Large proportions of the volatility of Latin American firms depend on factors beyond their control, and many of these factors are even beyond the particular country and are truly global. However, we have shown that from a practical point of view, due to the efficiency of capital markets, local indices capture basically all relevant information about the external influences. More precisely, standard local indices (i.e. Merval for Argentina, Bovespa for Brazil, etc.) plus industry indices capture essentially the same amount of information as a set of global, regional and local indices. The importance of this result is that it shows that the set of relevant market information is contained in the stocks of local companies that conform such standard local indices. This is consistent with the hypothesis of efficient capital markets. But this does not mean that these standard indices are the best possible filtering devises. It only means that the relevant information is there. The best possible filtering devise for a specific firm would be a tailor made optimized index. Such an optimized index -where the weight of each stock is itself the solution of an optimization problem- will do a better job at filtering out the noise. We should regard the generic solutions presented here as a lower bound to the efficiency of the solutions of the filtering problem. A key lesson then is that such optimized index should be constructed only out of local stocks. This finding gives us license to work with very simple models, which would be critically important when searching for optimized indices tailor made for specific firms.

The final question we addressed concerned the stability of our solutions. In order to design indexed, equity-based incentive contracts, we need to know how stable are the indices used in these contracts. In terms of our models, this meant to evaluate the stability of the beta parameters obtained from the regressions. Our analysis revealed that these beta parameters do change significantly with time. The problem when these parameters are unstable is that an indexed option compensation contract may become sub-optimal soon. Therefore, we interpreted these results as indication that optimal indexed option contracts should have 
durations much shorter than what tends to be standard for regular stock option plans (about ten years).

\section{Acknowledgements}

One of the authors, S.P., would like to acknowledge William M. Mercer Human Resources Consulting for sponsoring this work. 